\title{
EXTERNAL DAN INTERNAL DIRECT PRODUCTS PADA GRUP
}

\author{
HESTI SRI HANDANI, I MADE ARNAWA, NOVA NOLIZA BAKAR \\ Program Studi S1 Matematika, \\ Fakultas Matematika dan Ilmu Pengetahuan Alam, Universitas Andalas, \\ Kampus UNAND Limau Manis Padang, Indonesia. \\ email : hestihandanii@gmail.com,arnawa@sci.unand.ac.id,novanoliza@sci.unand.ac.id
}

Diterima 15 September 2020 Direvisi 14 Oktober 2020 Dipublikasikan 21 Oktober 2020

\begin{abstract}
Abstrak. Misalkan $G_{1}$ dan $G_{2}$ suatu grup dengan operasi biner, maka grup $\left(G_{1} \times G_{2}, \circledast\right)$ disebut grup external direct products dari $G_{1}$ dan $G_{2}$. Misalkan $G$ adalah suatu grup dengan operasi biner, dan $H_{1}$ dan $H_{2}$ subgrup dari $G$. $G$ disebut internal direct products dari $H_{1}$ dan $H_{2}$, jika setiap elemen dari $H_{1}$ komutatif dengan setiap elemen dari $H_{2}$, dan setiap elemen dari $G$ dapat dinyatakan secara tunggal sebanyak hasil kali dari elemen $H_{1}$ dan $H_{2}$.

Kata Kunci: Grup, Subgrup, Koset, Subgrup Normal, Fungsi, Isomorfisma Grup, External Direct Products, Internal Direct Products
\end{abstract}

\section{Pendahuluan}

Himpunan tak kosong $G$ disebut grup jika di $G$ didefinisikan suatu operasi biner sedemikian sehingga himpunan $G$ dengan operasi biner memenuhi sifat tertutup, asosiatif, terdapat unsur identitas di $G$, dan untuk setiap unsur di $G$ mempunyai invers (balikan). Jika berlaku sifat komutatif pada suatu grup, maka grup tersebut disebut grup abelian. Subgrup $H$ adalah himpunan bagian dari $G$ jika dengan operasi biner yang sama dengan $G$, juga membentuk grup [4].

Misalkan $G_{1}$ dan $G_{2}$ suatu grup dengan operasi biner, maka grup $\left(G_{1} \times G_{2}, \circledast\right)$ disebut grup external direct products dari $G_{1}$ dan $G_{2}$. Misalkan $G$ adalah suatu grup dengan operasi biner, dan $H_{1}$ dan $H_{2}$ subgrup dari $G$. $G$ disebut internal direct products dari $H_{1}$ dan $H_{2}$, jika setiap elemen dari $H_{1}$ komutatif dengan setiap elemen dari $H_{2}$, dan setiap elemen dari $G$ dapat dinyatakan secara tunggal sebanyak hasil kali dari elemen $H_{1}$ dan $H_{2}[6]$.

${ }^{*}$ penulis korespondensi 


\section{Landasan Teori}

\subsection{Grup dan Subgrup}

Definisi 2.1. [4] Suatu himpunan tidak kosong $G$ disebut suatu grup jika pada $G$ dapat didefinisikan suatu operasi biner ditulis $*$, sedemikian sehingga:

(1) Jika $a, b \in G$, maka $a * b \in G$ (Sifat Tertutup).

(2) Jika $a, b, c \in G$, maka $a *(b * c)=(a * b) * c$ (Sifat Asosiatif).

(3) Terdapat suatu unsur e di $G$, sedemikian sehingga $a * e=e * a=a$ untuk semua $a \in G$ (Keberadaan Unsur Identitas).

(4) Untuk setiap $a \in G$, terdapat suatu unsur $a^{-1} \in G$, sedemikian sehingga $a *$ $a^{-1}=a^{-1} * a=e$ (Keberadaan Unsur Invers).

Definisi 2.2. [4] Suatu grup $G$ disebut grup abelian (grup komutatif) jika untuk setiap $a, b \in G$ berlaku $a b=b a$.

Lema 2.3. [4] Jika G suatu grup, maka

(1) Unsur identitas di $G$ adalah tunggal.

(2) Untuk setiap $a \in G$ memiliki invers tunggal di $G$.

(3) Untuk setiap $a \in G,\left(a^{-1}\right)^{-1}=a$.

(4) Untuk setiap $a, b \in G,(a \cdot b)^{-1}=b^{-1} \cdot a^{-1}$.

Definisi 2.4. [4] Suatu himpunan bagian tak kosong $H$ dari $G$ dikatakan subgrup dari $G$, jika $H$ dengan operasi biner yang sama dengan $G$ juga membentuk grup.

Lema 2.5. [4] Suatu himpunan bagian tak kosong $H$ dari $G$ disebut subgrup dari $G$, jika dan hanya jika:

(1) Untuk setiap $a, b \in H$, berlaku $a b \in H$.

(2) Untuk setiap $a \in H$, berlaku $a^{-1} \in H$.

Lema 2.6. [4] Misalkan $H, K$ subgrup dari $G$, maka $H \cap K$ subgrup dari $G$.

\subsection{Koset, Subgrup Normal, dan Grup Faktor}

Berikut akan dijelaskan sifat-sifat dari Koset, Subgrup Normal, dan Grup Faktor.

Definisi 2.7. [2] Misalkan $G$ suatu grup, dan $H$ subgrup dari G. Untuk setiap $a \in G$,

$$
H a=\{h a \mid h \in H\}
$$

adalah koset kanan dari $H$ oleh a,

$$
a H=\{a h \mid h \in H\}
$$

adalah koset kiri dari $H$ oleh a.

Definisi 2.8. [4] Suatu subgrup $N$ dari $G$ dikatakan subgrup normal dari $G$ jika untuk setiap $g \in G$ dan $n \in N$ berlaku gng $^{-1} \in N$. 
Lema 2.9. [4] Subgrup $N$ dari $G$ adalah subgrup normal dari $G$ jika dan hanya jika perkalian dari dua koset kanan dari $N$ di $G$ adalah koset kanan di $G$.

Teorema 2.10. [4] Jika $G$ adalah suatu grup, $N$ adalah subgrup normal dari $G$. Maka $G / N=\{N g \mid g \in G$ disebut grup kuosien atau grup faktor dari $G$ oleh $N\}$.

\subsection{Fungsi}

Definisi 2.11. [1] Misalkan A dan B adalah dua himpunan tak kosong, $\phi$ dikatakan suatu fungsi dari $A$ ke $B$ jika setiap unsur di $A$ dipetakan secara tunggal ke suatu unsur di $B$, ditulis $\phi: A \rightarrow B$. Apabila $\phi$ memetakan suatu $x \in A$ ke suatu $y \in B$ maka y disebut peta dari $x$, ditulis dengan $\phi: x \mapsto y$, sedangkan $x$ disebut prapeta dari y. Himpunan $A$ dinamakan daerah asal (domain) dari fungsi $\phi$ dan himpunan $B$ dinamakan daerah hasil (range) dari fungsi $\phi$ tersebut.

Definisi 2.12. [3] Suatu fungsi dari himpunan A ke himpunan $B$ adalah satu-satu jika setiap elemen di B mempunyai paling banyak satu elemen dari $A$ dipetakan ke $B$, dan dikatakan pada $B$ jika setiap elemen dari $B$ mempunyai paling sedikit satu elemen dari $A$ dipetakan ke $B$.

\subsection{Isomorfisma Grup}

Definisi 2.13. [4] Suatu pemetaan $\phi$ dari grup $G$ ke grup $G^{\prime}\left(\phi: G \rightarrow G^{\prime}\right)$ dikatakan homomorfisma jika untuk setiap $a, b \in G$ berlaku

$$
\phi(a b)=\phi(a) \phi(b) .
$$

Lema 2.14. [4] Jika $\phi$ adalah pemetaan homomorfisma dari $G$ ke $G^{\prime}$ maka:

(1) $\phi(e)=e^{\prime}$, e' suatu unsur identitas dari $G^{\prime}$.

(2) $\phi\left(x^{-1}\right)=\phi(x)^{-1}$, untuk setiap $x \in G$.

Lema 2.15. [4] Misalkan $G$ adalah suatu grup, $N$ adalah subgrup normal dari $G$. Didefinisikan $\phi$ suatu pemetaan dari $G$ ke $G / N$ oleh $\phi(x)=N x$, untuk setiap $x \in G$, maka $\phi$ adalah homomorfisma dari $G$ pada $G / N$.

Definisi 2.16. [4] Jika $\phi$ adalah homomorfisma dari $G$ ke $G^{\prime}$, maka kernel $\phi, K_{\phi}$, didefinisikan sebagai $K_{\phi}=\left\{x \in G \mid \phi(x)=e^{\prime}, e^{\prime}=\right.$ unsur identitas di $\left.G^{\prime}\right\}$.

Lema 2.17. [4] Jika ф suatu homomorfisma dari $G$ ke $G^{\prime}$ dengan kernel $K$, maka $K$ adalah subgrup normal dari $G$.

Definisi 2.18. [3] Suatu isomorfisma $\phi: G \rightarrow G^{\prime}$ adalah suatu homomorfisma yang satu-satu dan pada. Dinotasikan dengan $G \cong G^{\prime}$.

Teorema 2.19. [5] Suatu homomorfisma $\phi: G \rightarrow G^{\prime}$ adalah satu-satu jika dan hanya jika $K_{\phi}=\{e\}, e \in G$.

Teorema 2.20. [4] Misalkan $\phi$ suatu homomorfisma pada dari $G$ ke $G^{\prime}$ dengan kernel $K$. Maka $G / K \cong G^{\prime}$. 


\section{Pembahasan}

\subsection{External Direct Products}

Definisi 3.1. [6] Misalkan $G_{1}$ dan $G_{2}$ adalah dua grup sebarang. Didefinisikan product dari dua himpunan ini, $G_{1} \times G_{2}$ sebagai

$$
G_{1} \times G_{2}=\left\{\left(a_{1}, a_{2}\right) \mid a_{1} \in G_{1} \text { dan } a_{2} \in G_{2}\right\}
$$

Teorema 3.2. [6] Misalkan $G_{1}$ dan $G_{2}$ adalah dua grup. Definisikan suatu operasi perkalian $\circledast$ pada $G_{1} \times G_{2}$ sebagai berikut:

$$
\left(a_{1}, a_{2}\right) \circledast\left(b_{1}, b_{2}\right)=\left(a_{1} b_{1}, a_{2} b_{2}\right)
$$

untuk setiap elemen $\left(a_{1}, a_{2}\right),\left(b_{1}, b_{2}\right) \in G_{1} \times G_{2}$.

Maka $\left(G_{1} \times G_{2}, \circledast\right)$ suatu grup dan disebut grup external direct products dari $G_{1}$ dan $G_{2}$.

Bukti. Misalkan $G_{1}$ dan $G_{2}$ adalah dua grup dan $G_{1} \times G_{2}=\left\{\left(a_{1}, a_{2}\right) \mid a_{1} \in G_{1}\right.$ dan $\left.a_{2} \in G_{2}\right\}$.

Akan ditunjukkan $\left(G_{1} \times G_{2}, \circledast\right)$ suatu grup dan disebut grup external direct products dari $G_{1}$ dan $G_{2}$

(i) (Sifat Tertutup) Misalkan $\left(a_{1}, a_{2}\right)$ dan $\left(b_{1}, b_{2}\right)$ merupakan elemen dari $G_{1} \times G_{2}$, maka $a_{1}, b_{1} \in G_{1}$ dan $a_{2}, b_{2} \in G_{2}$.

Perhatikan bahwa:

$$
\left(a_{1}, a_{2}\right) \circledast\left(b_{1}, b_{2}\right)=\left(a_{1} b_{1}, a_{2} b_{2}\right)
$$

Karena $G_{1}$ dan $G_{2}$ suatu grup, maka $a_{1} b_{1} \in G_{1}$ dan $a_{2} b_{2} \in G_{2}$, sehingga $\left(a_{1}, a_{2}\right) \circledast\left(b_{1}, b_{2}\right) \in G_{1} \times G_{2}$

Jadi untuk setiap $\left(a_{1}, a_{2}\right),\left(b_{1}, b_{2}\right) \in G_{1} \times G_{2}$ berlaku $\left(a_{1}, a_{2}\right) \circledast\left(b_{1}, b_{2}\right) \in G_{1} \times G_{2}$ sehingga $G_{1} \times G_{2}$ bersifat tertutup.

(ii) (Sifat Asosiatif) Misalkan $\left(a_{1}, a_{2}\right),\left(b_{1}, b_{2}\right)$ dan $\left(c_{1}, c_{2}\right)$ merupakan elemen dari $G_{1} \times G_{2}$, maka $a_{1}, b_{1}, c_{1} \in G_{1}$ dan $a_{2}, b_{2}, c_{2} \in G_{2}$.

Perhatikan bahwa:

$$
\begin{aligned}
\left\{\left(a_{1}, a_{2}\right) \circledast\left(b_{1}, b_{2}\right)\right\} \circledast\left(c_{1}, c_{2}\right) & =\left(a_{1} b_{1}, a_{2} b_{2}\right) \circledast\left(c_{1}, c_{2}\right) \\
& =\left(\left(a_{1} b_{1}\right) c_{1},\left(a_{2} b_{2}\right) c_{2}\right) \\
& =\left(a_{1}\left(b_{1} c_{1}\right), a_{2}\left(b_{2} c_{2}\right)\right) \\
& =\left(a_{1}, a_{2}\right) \circledast\left(b_{1} c_{1}, b_{2} c_{2}\right) \\
& =\left(a_{1}, a_{2}\right) \circledast\left\{\left(b_{1}, b_{2}\right) \circledast\left(c_{1}, c_{2}\right)\right\}
\end{aligned}
$$

Jadi untuk setiap $\left(a_{1}, a_{2}\right),\left(b_{1}, b_{2}\right)$ dan $\left(c_{1}, c_{2}\right) \in G_{1} \times G_{2}$ berlaku $\left\{\left(a_{1}, a_{2}\right) \circledast\right.$ $\left.\left(b_{1}, b_{2}\right)\right\} \circledast\left(c_{1}, c_{2}\right)=\left(a_{1}, a_{2}\right) \circledast\left\{\left(b_{1}, b_{2}\right) \circledast\left(c_{1}, c_{2}\right)\right\}$.

(iii) (Keberadaan Unsur Identitas) Misalkan $e_{1}$ identitas di $G_{1}, e_{2}$ identitas di $G_{2}$, maka $\left(e_{1}, e_{2}\right) \in G_{1} \times G_{2}$. Selain itu, untuk setiap $\left(a_{1}, a_{2}\right) \in G_{1} \times G_{2}$ berlaku

(a) $\left(a_{1}, a_{2}\right) \circledast\left(e_{1}, e_{2}\right)=\left(a_{1} e_{1}, a_{2} e_{2}\right)=\left(a_{1}, a_{2}\right)$

(b) $\left(e_{1}, e_{2}\right) \circledast\left(a_{1}, a_{2}\right)=\left(e_{1} a_{1}, e_{2} a_{2}\right)=\left(a_{1}, a_{2}\right)$ 
Jadi untuk setiap $\left(a_{1}, a_{2}\right) \in G_{1} \times G_{2}$ terdapat $\left(e_{1}, e_{2}\right) \in G_{1} \times G_{2}$ sehingga $\left(a_{1}, a_{2}\right) \circledast\left(e_{1}, e_{2}\right)=\left(e_{1}, e_{2}\right) \circledast\left(a_{1}, a_{2}\right)=\left(a_{1}, a_{2}\right)$.

(iv) (Keberadaan Unsur Invers) Misalkan $\left(a_{1}, a_{2}\right)$ adalah suatu elemen pada $G_{1} \times G_{2}$, maka $a_{1} \in G_{1}$ dan $a_{2} \in G_{2}$.

Karena $a_{1} \in G_{1}$ dan $G_{1}$ grup, maka berlaku $a_{1}^{-1} \in G_{1}$.

Karena $a_{2} \in G_{2}$ dan $G_{2}$ grup, maka berlaku $a_{2}^{-1} \in G_{2}$.

Perhatikan bahwa:

(a) $\left(a_{1}, a_{2}\right) \circledast\left(a_{1}^{-1}, a_{2}^{-1}\right)=\left(a_{1} a_{1}^{-1}, a_{2} a_{2}^{-1}\right)=\left(e_{1}, e_{2}\right)$

(b) $\left(a_{1}^{-1}, a_{2}^{-1}\right) \circledast\left(a_{1}, a_{2}\right)=\left(a_{1}^{-1} a_{1}, a_{2}^{-1} a_{2}\right)=\left(e_{1}, e_{2}\right)$

Jadi untuk setiap $\left(a_{1}, a_{2}\right) \in G_{1} \times G_{2}$ terdapat $\left(a_{1}^{-1}, a_{2}^{-1}\right) \in G_{1} \times G_{2}$ sehingga $\left(a_{1}, a_{2}\right) \circledast\left(a_{1}^{-1}, a_{2}^{-1}\right)=\left(a_{1}^{-1}, a_{2}^{-1}\right) \circledast\left(a_{1}, a_{2}\right)=\left(e_{1}, e_{2}\right)$.

Karena (i), (ii), (iii), dan (iv), diperoleh $\left(G_{1} \times G_{2}, \circledast\right)$ suatu grup dan disebut grup external direct products dari $G_{1}$ dan $G_{2}$.

Contoh 3.3. Misalkan $U(6)=\{1,5\}$ merupakan grup terhadap operasi perkalian modulo 6 dan $U(8)=\{1,3,5,7\}$ merupakan grup terhadap operasi perkalian modulo 8. Akan ditunjukkan $(U(6) \times U(8), \circledast)$ suatu grup external direct products dari $U(6)$ dan $U(8)$. Berdasarkan Definisi 3.1, diperoleh $U(6) \times U(8)=$ $\{(1,1),(1,3),(1,5),(1,7),(5,1),(5,3),(5,5),(5,7)\}$ dengan operasi $\circledast$.

(i) Akan ditunjukkan setiap unsur di $(U(6) \times U(8), \circledast)$ bersifat tertutup. Dibawah ini akan diuraikan tabel perkalian $\circledast$ dari setiap unsur di $U(6) \times U(8)$.

Tabel 1. Hasil perkalian $\circledast$ setiap unsur di $U(6) \times U(8)$

\begin{tabular}{|c|c|c|c|c|c|c|c|c|}
\hline$\circledast$ & $(1,1)$ & $(1,3)$ & $(1,5)$ & $(1,7)$ & $(5,1)$ & $(5,3)$ & $(5,5)$ & $(5,7)$ \\
\hline$(1,1)$ & $(1,1)$ & $(1,3)$ & $(1,5)$ & $(1,7)$ & $(5,1)$ & $(5,3)$ & $(5,5)$ & $(5,7)$ \\
\hline$(1,3)$ & $(1,3)$ & $(1,1)$ & $(1,7)$ & $(1,5)$ & $(5,3)$ & $(5,1)$ & $(5,7)$ & $(5,5)$ \\
\hline$(1,5)$ & $(1,5)$ & $(1,7)$ & $(1,1)$ & $(1,3)$ & $(5,5)$ & $(5,7)$ & $(5,1)$ & $(5,3)$ \\
\hline$(1,7)$ & $(1,7)$ & $(1,5)$ & $(1,3)$ & $(1,1)$ & $(5,7)$ & $(5,5)$ & $(5,3)$ & $(5,1)$ \\
\hline$(5,1)$ & $(5,1)$ & $(5,3)$ & $(5,5)$ & $(5,7)$ & $(1,1)$ & $(1,3)$ & $(1,5)$ & $(1,7)$ \\
\hline$(5,3)$ & $(5,3)$ & $(5,1)$ & $(5,7)$ & $(5,5)$ & $(1,3)$ & $(1,1)$ & $(1,7)$ & $(1,5)$ \\
\hline$(5,5)$ & $(5,5)$ & $(5,7)$ & $(5,1)$ & $(5,3)$ & $(1,5)$ & $(1,7)$ & $(1,1)$ & $(1,3)$ \\
\hline$(5,7)$ & $(5,7)$ & $(5,5)$ & $(5,3)$ & $(5,1)$ & $(1,7)$ & $(1,5)$ & $(1,3)$ & $(1,1)$ \\
\hline
\end{tabular}

Dari Tabel 3.1.1, diketahui bahwa untuk setiap unsur $\left(a_{1}, a_{2}\right),\left(b_{1}, b_{2}\right) \in$ $U(6) \times U(8)$ berlaku $\left(a_{1}, a_{2}\right) \circledast\left(b_{1}, b_{2}\right) \in U(6) \times U(8)$ sehingga terbukti $(U(6) \times$ $U(8), \circledast)$ bersifat tertutup.

(ii) Akan ditunjukkan setiap unsur di $(U(6) \times U(8), \circledast)$ bersifat asosiatif. Berdasarkan Tabel 3.1.1, untuk setiap unsur $\left(a_{1}, a_{2}\right),\left(b_{1}, b_{2}\right),\left(c_{1}, c_{2}\right) \in U(6) \times$ $U(8)$ berlaku $\left\{\left(a_{1}, a_{2}\right) \circledast\left(b_{1}, b_{2}\right)\right\} \circledast\left(c_{1}, c_{2}\right)=\left(a_{1}, a_{2}\right) \circledast\left\{\left(b_{1}, b_{2}\right) \circledast\left(c_{1}, c_{2}\right)\right\}$. Ini berarti $(U(6) \times U(8), \circledast)$ bersifat asosiatif.

(iii) Akan ditunjukkan setiap unsur di $(U(6) \times U(8), \circledast)$ memiliki unsur identitas. Berdasarkan Tabel 3.1.1, diperoleh $(1,1)$ merupakan unsur identitas di $(U(6) \times$ $U(8)$. Ini berarti $(U(6) \times U(8), \circledast)$ memiliki unsur identitas. 
(iv) Akan ditunjukkan setiap unsur di $(U(6) \times U(8)$, $)$ memiliki invers. Berdasarkan Tabel 3.1.1, untuk setiap $\left(a_{1}, a_{2}\right) \in U(6) \times U(8)$ berlaku $\left(a_{1}, a_{2}\right)^{-1} \in U(6) \times$ $U(8)$. Ini berarti $(U(6) \times U(8), \circledast)$ memiliki invers.

Berdasarkan (i), (ii), (iii), dan (iv), diperoleh $(U(6) \times U(8)$, $)$ suatu grup external direct products dari $U(6)$ dan $U(8)$.

Teorema 3.4. [6] Misalkan $G_{1}$ dan $G_{2}$ adalah grup. Misalkan $e_{1}$ dan $e_{2}$ adalah elemen identitas masing-masing pada $G_{1}$ dan $G_{2}$, maka $G_{1} \times\left\{e_{2}\right\}$ dan $\left\{e_{1}\right\} \times G_{2}$ pada $G_{1} \times G_{2}$ adalah subgrup normal dari $G_{1} \times G_{2}$.

Teorema 3.5. [6] Misalkan $G_{1}$ dan $G_{2}$ merupakan grup. Misalkan $e_{1}$ dan $e_{2}$ adalah elemen identitas masing-masing pada $G_{1}$ dan $G_{2}$, maka $G_{1} \times\left\{e_{2}\right\} \cong G_{1}$ dan $\left\{e_{1}\right\} \times$ $G_{2} \cong G_{2}$.

Teorema 3.6. [6] Misalkan $G_{1}$ dan $G_{2}$ merupakan grup. Misalkan $e_{1}$ dan $e_{2}$ adalah elemen identitas masing-masing pada $G_{1}$ dan $G_{2}$, maka

(a) $\left(G_{1} \times\left\{e_{2}\right\}\right) \cap\left(\left\{e_{1}\right\} \times G_{2}\right)=\left\{\left(e_{1}, e_{2}\right)\right\}$.

(b) $\forall x \in G_{1} \times\left\{e_{2}\right\}$ dan $y \in\left\{e_{1}\right\} \times G_{2}$ berlaku $x \circledast y=y \circledast x$.

(c) $\forall z \in G_{1} \times G_{2}$, z dapat ditulis secara tunggal sebagai $z=x \circledast y$ untuk suatu $x \in G_{1} \times\left\{e_{2}\right\}$ dan $y \in\left\{e_{1}\right\} \times G_{2}$.

(d) $G_{1} \times G_{2} \cong G_{2} \times G_{1}$.

\subsection{Internal Direct Products}

Definisi 3.7. [6] Misalkan $(G, *)$ adalah suatu grup. Grup $(G, *)$ dikatakan internal direct products dari dua subgrup $H_{1}$ dan $H_{2}$ jika:

(i) setiap elemen dari $H_{1}$ komutatif dengan setiap elemen dari $\mathrm{H}_{2}$.

(ii) setiap elemen dari $G$ dapat dinyatakan secara tunggal sebanyak hasil kali dari elemen $\mathrm{H}_{1}$ dan $\mathrm{H}_{2}$.

Contoh 3.8. Misalkan $G=\left\{I,\left(\begin{array}{ll}a & b\end{array}\right),\left(\begin{array}{ll}c & d\end{array}\right),\left(\begin{array}{ll}a & b\end{array}\right) \circ\left(\begin{array}{ll}c & d\end{array}\right)\right\}$ suatu grup yang memuat

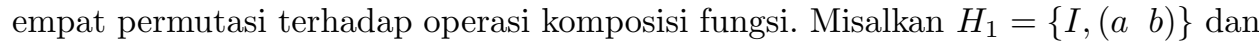
$H_{2}=\left\{I,\left(\begin{array}{ll}c & d\end{array}\right)\right\}$ yang merupakan subgrup dari $G$. Akan ditunjukkan $G$ internal direct products dari $H_{1}$ dan $H_{2}$.

a) Akan ditunjukkan setiap elemen dari $H_{1}$ komutatif dengan setiap elemen dari $H_{2}$. Di bawah ini akan diuraikan tabel komposisi setiap unsur di $G$.

Tabel 2. Hasil komposisi setiap unsur di $G$

\begin{tabular}{|c|c|c|c|}
\hline$\circ$ & $I$ & $\left(\begin{array}{ll}a & b\end{array}\right)$ & $\left(\begin{array}{ll}c & d\end{array}\right)$ \\
\hline$I$ & $I$ & $\left(\begin{array}{ll}a & b\end{array}\right)$ & $\left(\begin{array}{ll}c & d\end{array}\right)$ \\
\hline$\left(\begin{array}{ll}a & b\end{array}\right)$ & $\left(\begin{array}{ll}a & b\end{array}\right)$ & $I$ & $\left(\begin{array}{lll}a & b\end{array}\right)\left(\begin{array}{ll}c & d\end{array}\right)$ \\
\hline$\left(\begin{array}{ll}c & d\end{array}\right)$ & $\left(\begin{array}{ll}c & d\end{array}\right)$ & $\left(\begin{array}{lll}a & b\end{array}\right)\left(\begin{array}{ll}c & d\end{array}\right)$ & $I$ \\
\hline
\end{tabular}


Perhatikan bahwa:

$$
\left(\begin{array}{ll}
a & b
\end{array}\right) \circ\left(\begin{array}{ll}
c & d
\end{array}\right)=\left(\begin{array}{llll}
a & b & c & d \\
b & a & c & d
\end{array}\right) \circ\left(\begin{array}{llll}
a & b & c & d \\
a & b & d & c
\end{array}\right)=\left(\begin{array}{llll}
a & b & c & d \\
b & a & d & c
\end{array}\right)
$$

dan

$$
\left(\begin{array}{ll}
c & d
\end{array}\right) \circ\left(\begin{array}{ll}
a & b
\end{array}\right)=\left(\begin{array}{llll}
a & b & c & d \\
a & b & d & c
\end{array}\right) \circ\left(\begin{array}{llll}
a & b & c & d \\
b & a & c & d
\end{array}\right)=\left(\begin{array}{llll}
a & b & c & d \\
b & a & d & c
\end{array}\right)
$$

Dari uraian diatas dapat dilihat bahwa setiap elemen dari $H_{1}$ komutatif dengan setiap elemen dari $H_{2}$.

b) Akan ditunjukkan setiap elemen dari $G$ dapat dinyatakan secara tunggal sebanyak hasil kali dari elemen dari $H_{1}$ dan $H_{2}$.

Perhatikan bahwa:

$$
\begin{aligned}
I & =I \circ I \\
\left(\begin{array}{ll}
a & b
\end{array}\right) & =\left(\begin{array}{ll}
a & b
\end{array}\right) \circ I \\
\left(\begin{array}{ll}
c & d
\end{array}\right) & =I \circ\left(\begin{array}{ll}
c & d
\end{array}\right) \\
\left(\begin{array}{lll}
a & b
\end{array}\right) \circ\left(\begin{array}{ll}
c & d
\end{array}\right) & =\left(\begin{array}{ll}
a & b
\end{array}\right) \circ\left(\begin{array}{ll}
c & d
\end{array}\right)
\end{aligned}
$$

Dari uraian diatas dapat dilihat bahwa setiap elemen dari $G$ dapat dinyatakan secara tunggal sebanyak hasil kali dari elemen dari $H_{1}$ dan $H_{2}$.

Teorema 3.9. [6] Misalkan grup G suatu internal direct products dari dua subgrup $\mathrm{H}_{1}$ dan $\mathrm{H}_{2}$, maka

(i) $H_{1} \cap H_{2}=\{e\}$.

(ii) $H_{1} \times H_{2} \cong G$.

Teorema 3.10. [6] Misalkan grup $G$ suatu internal direct products dari dua subgrup $H_{1}$ dan $H_{2}$. Maka $H_{1}$ dan $H_{2}$ subgrup normal dari $G$.

Bukti. Misalkan grup $G$ suatu internal direct products dari dua subgrup $H_{1}$ dan $\mathrm{H}_{2}$.

a) Akan ditunjukkan $H_{1}$ subgrup normal dari $G$.

Ambil sebarang $a \in H_{1}$ dan $x \in G$.

Karena $G=H_{1} \times H_{2}$ maka $x=h_{1} h_{2}$ untuk suatu $h_{1} \in H_{1}$ dan $h_{2} \in H_{2}$.

Perhatikan bahwa:

$$
\begin{aligned}
x a x^{-1} & =\left(h_{1} h_{2}\right) a\left(h_{1} h_{2}\right)^{-1} \\
& =h_{1} h_{2} a h_{2}^{-1} h_{1}^{-1} \\
& =h_{1} a h_{2} h_{2}^{-1} h_{1}^{-1} \\
& =h_{1} a e h_{1}^{-1} \\
& =h_{1} a h_{1}^{-1}
\end{aligned}
$$

Karena $h_{1}, a, h_{1}^{-1} \in H_{1}$ dan $H_{1}$ subgrup maka $h_{1} a h_{1}^{-1} \in H_{1}$. Ini berarti $H_{1}$ subgrup normal dari $G$. 
b) Akan ditunjukkan $\mathrm{H}_{2}$ subgrup normal dari $G$.

Ambil sebarang $a \in H_{2}$ dan $x \in G$.

Karena $G=H_{1} \times H_{2}$ maka $x=h_{1} h_{2}$ untuk suatu $h_{1} \in H_{1}$ dan $h_{2} \in H_{2}$.

Perhatikan bahwa:

$$
\begin{aligned}
\operatorname{xax}^{-1} & =\left(h_{1} h_{2}\right) a\left(h_{1} h_{2}\right)^{-1} \\
& =h_{1} h_{2} a h_{2}^{-1} h_{1}^{-1} \\
& =h_{2} h_{1} a h_{1}^{-1} h_{2}^{-1} \\
& =h_{2} a h_{1} h_{1}^{-1} h_{2}^{-1} \\
& =h_{2} a e h_{2}^{-1} \\
& =h_{2} a h_{2}^{-1}
\end{aligned}
$$

Karena $h_{2}, a, h_{2}^{-1} \in H_{2}$ dan $H_{2}$ subgrup maka $h_{2} a h_{2}^{-1} \in H_{2}$.

Ini berarti $H_{2}$ subgrup normal dari $G$.

Teorema 3.11. [6] Misalkan grup G suatu internal direct products dari dua subgrup $\mathrm{H}_{1}$ dan $\mathrm{H}_{2}$. Maka

i) $G / H_{2} \cong H_{1}$.

ii) $G / H_{1} \cong H_{2}$.

\section{Kesimpulan}

(1) Jika $G_{1}$ dan $G_{2}$ suatu grup maka $\left(G_{1} \times G_{2}\right.$, $)$ suatu grup dan disebut grup external direct products dari $G_{1}$ dan $G_{2}$.

(2) Jika $G_{1}$ dan $G_{2}$ suatu grup dengan $e_{1}$ dan $e_{2}$ identitas pada masing-masing $G_{1}$ dan $G_{2}$ maka

(a) $G_{1} \times\left\{e_{2}\right\}$ dan $\left\{e_{1}\right\} \times G_{2}$ pada $G_{1} \times G_{2}$ adalah subgrup normal dari $G_{1} \times G_{2}$.

(b) $G_{1} \times\left\{e_{2}\right\}$ isomorfik ke $G_{1}$ dan $\left\{e_{1}\right\} \times G_{2}$ isomorfik ke $G_{2}$.

(c) $\left(G_{1} \times\left\{e_{2}\right\}\right) \cap\left(\left\{e_{1}\right\} \times G_{2}\right)=\left\{\left(e_{1}, e_{2}\right)\right\}$.

(d) $\forall x \in G_{1} \times\left\{e_{2}\right\}$ dan $y \in\left\{e_{1}\right\} \times G_{2}$ berlaku $x \circledast y=y \circledast x$.

(e) $\forall z \in G_{1} \times G_{2}$, $z$ dapat ditulis secara tunggal sebagai $z=x \circledast y$ untuk suatu $x \in G_{1} \times\left\{e_{2}\right\}$ dan $y \in\left\{e_{1}\right\} \times G_{2}$.

(f) $G_{1} \times G_{2}$ isomorfik ke $G_{2} \times G_{1}$.

(3) Jika $(G, *)$ merupakan suatu grup internal direct products dari dua subgrup $H_{1}$ dan $H_{2}$ maka

(a) Irisan dari $H_{1}$ dan $H_{2}$ yaitu elemen identitas $e$ dari $G$.

(b) $H_{1} \times H_{2}$ isomorfik ke $G$.

(c) $H_{1}$ dan $H_{2}$ adalah subgrup normal dari $G$.

(d) $G / H_{1}$ isomorfik ke $H_{2}$ dan $G / H_{2}$ isomorfik ke $H_{1}$.

(4) Setiap internal direct products pada $G$ isomorfik dengan external direct products.

\section{Daftar Pustaka}

[1] Bartle, R.G. dan D.R. Sherbert. 2000. Introduce to Real Analysis 3rd Edition. John Wiley and Sons, United States of America. 
[2] Ehrlich, G. 1991. Fundamental Concepts of Abstract Algebra. PWS - KENT Publishing Company, United States of America.

[3] Fraleigh, J. B. dan K, Victor. 1994. A First Course in Abstract Algebra, Fifth Edition. Addison - Wesley Publishing Company, United States of America.

[4] Herstein, I. N. 1975. Topics in Algebra, Second Edition. John Wiley \& Sons, New York.

[5] Khanna, V. K. dan Bhambri, S. K. 1993. A Course in Abstract Algebra, Fifth Edition. Vikas Publishing House PVT LTD, New Delhi.

[6] Raisinghania, M. D. dan Aggarwal, R. S. 1980. Modern Algebra. S. Chand \& Company LTD, New Delhi. 